\title{
FATORES DE GERAÇÃO DE INOVAÇÃO EM MICRO E PEQUENAS EMPRESAS FAMILIARES: ANÁLISE NO CONTEXTO DE UM MUNÍCIPIO DE PEQUENO PORTE DO RIO GRANDE DO SUL
}

\author{
FACTORS THAT GENERATE INNOVATION IN MICRO AND SMALL FAMILY BUSINESSES: \\ ANALYSIS IN A SMALL CITY OF RIO GRANDE DO SUL
}

\author{
Tainara Kaspary \\ Faculdade Meridional, Passo Fundo, RS, Brasil, taikaspary@hotmail.com \\ Denize Grzybovski \\ Universidade de Passo Fundo, Passo Fundo, RS, Brasil, gdenize@upf.br
}

Talita Bernardi Goettems

Universidade de Passo Fundo, Passo Fundo, RS, Brasil, talitabernardi18@hotmail.com

Nadiesca Manica dos Santos

Universidade de Passo Fundo, Passo Fundo, RS, Brasil, nady_gtk@hotmail.com

DOI: http://dx.doi.org/10.31512/gesto.v9i1.282

Recebido em: 10/03/2020

Aceito em: 28/10/2020

\begin{abstract}
Resumo: O objetivo do artigo é verificar, nas micro e pequenas empresas familiares (MPEFs), os fatores promotores de inovação considerando as questóes de contexto econômico, de segmento e de cultura do lugar como influenciadores da gestão. Trata-se de uma pesquisa social aplicada, do tipo levantamento, cujo espaço da pesquisa foi determinada pela perspectiva do território. Os dados foram submetidos à análise estatística. Os resultados demonstraram que MPEFs geram inovação incremental com base em processos informais, por meio da visão empreendedora dos seus gestores, e confirmaram os fatores de natureza econômica como os principais obstáculos para gerar inovação. Ainda, os dados indicam que a necessidade é o principal fator de geração de inovação pelas MPEFs. Conclui-se que o tipo de inovação gerada pelas MPEFs é incremental e demonstram dificuldade na geração de inovação disruptiva em razão da ordem econômica percebida. O estudo apresenta uma contribuição prática no desenho de políticas públicas no campo da inovaçáo com foco nas micro e pequenas empresas. Ainda, para pesquisas futuras, sugere-se aprofundar os estudos utilizando os fundamentos teóricos da capacidade absortiva para refletir sobre o papel do empreendedor na geração da inovação.
\end{abstract}

Palavras-chave: Tipo de inovação. Empresa familiar. Gestão de pequenas empresas. Fatores de geração de inovação.

Abstract: The article aims to verify the factors that promote innovation, considering the issues of economic context, segment and culture of the place as influencing management in micro and small family businesses. For this, it is an exploratory research whose space of research was determined by the perspective of the territory. The data were submitted to statistical analysis. The results showed that micro and small family businesses generate incremental innovation based on informal processes, through the entrepreneurial vision of their managers and confirmed the economic factors as the main obstacles to generate innovation. Still, the data indicates that, among the companies that generate innovation, the need is the main motivator. It is concluded that the type of innovation generated by micro and small family businesses is incremental and show difficulty in generating disruptive innovation due to the 
perceived economic order. The study presents a practical contribution to public policies in the field of innovation with a focus on micro and small companies. For future research, it is suggested to deepen the studies using the theoretical foundations of absorptive capacity to reflect on the role of the entrepreneur in generating innovation.

Keywords: Innovation types. Family business. Small business management. Factors influencing innovation.

\section{Introdução}

No contexto socioeconômico atual em que as empresas estáo inseridas, impulsionado pela globalização e mudanças comportamentais que conduziram à troca de informações e a melhorias, a inovação é um imperativo para o desempenho organizacional, inclusive em empresas familiares (Hatak, Kautonen, Fink, \& Kansikas (2016). Considerada uma força de manutenção e de crescimento e com poder de diferenciar empresas que atuam no mesmo segmento, a inovação apresenta relação positiva com desempenho organizacional, em especial no que se refere às melhorias em produtos, aumento no nível de participação de mercado e da capacidade produtiva (Hatak et al., 2016; Campos, Santos, \& Donadon, 2018; Costa Silva, Bezerra Ribeiro, Frascaroli, \& Moraes Filho, 2018).

O mesmo argumento nem sempre é válido para explicar a performance organizacional em relação ao porte e tipo de gestão. Microempresa e pequenas empresas familiares (MPEFs), não apresentam uniformidade em seu comportamento inovador (Frank, Kessler, Bachner, Fuetsch, \& Suess-Reyes, 2019). $\mathrm{Na}$ relação do porte da empresa com a singularidade da empresa familiar (Chua, Chrisman, \& Sharma, 1999) e a inovação, pouco tem sido estudado.

A literatura consultada indica lacunas de pesquisa a serem exploradas nesse campo (PadillaMeléndez, Dieguez-Soto, \& Garrido-Moreno, 2015). Com vistas a suprir essa lacuna nos estudos sobre inovação, argumentamos que MPEFs não geram inovaçáo disruptiva. Entendemos que MPEFs, mesmo que possuam a cultura de compromisso vinculada à performance econômica-financeira (Hatak et al., 2016; Alves \& Gama, 2020), têm recursos financeiros limitados e controles internos fracamente estruturados (Ayres, Cruz, Santos, \& Leone, 2018). Essa combinação de recursos representa uma configuração estrutural que dificulta a geração de indicadores para a tomada de decisóes com maior grau de risco (Parida, Westerberg, \& Frishammar, 2012), postura empresarial determinante na geração de inovação disruptiva.

Diferentes autores sustentam que o problema da inovação nas MPEFs se apresenta atrelado as suas fases do ciclo de vida, pela ausência/limitação de recursos para sustentar o próprio empreendimento (Alves \& Gama, 2020; Kammerlander \& Breugst, 2019; Oliveira, Escrivão, Nagano, \& Ferraudo, 2015). A superação dessa limitação se dá pela inovação aberta (Silva \& Dacorso, 2013), pelo papel dos empreendedores na transferência de informaçóes de valor (Ter Wal, Criscuolo, \& Salter, 2017) e pela seleção das fontes de conhecimento que alimentam o processo de inovação (Silva \& Dacorso, 2014, 2016; Audy, 2017).

O objetivo do presente artigo foi verificar os tipos de inovação nas MPEFs considerando as questóes de contexto (economia nacional e local, segmento e mercado de atuação, cultura e tradiçâo da família proprietária, outros) e os tipos de propriedade e de gestão (familiar/não familiar). Para tanto, o espaço da pesquisa foi limitado ao município de Marau, no estado do Rio Grande do Sul, pois a singularidade do 
porte de empresa e a configuração societária são determinantes das açôes em empresas familiares, como argumentam Alves e Gama (2020).

Os membros da família e o capital financeiro familiar fazem parte da estrutura e dinâmica organizacional em MPEFs (Alves \& Gama, 2020). As empresas de propriedade e gestão familiar apresentam singularidades que residem na própria família (Chua et al., 1999), explicadas pela interface de três sistemas (propriedade, gestão e família) que se entrecruzam (Gersick, Davis, Hampton, \& Lansberg, 1997) e determinam os estágios de crescimento e desenvolvimento (Zahra, Hayton, Neubaum, Dibrell \& Craig, 2008). Segundo Frank et al. (2019), a singularidade no estrato das empresas familiares inclui o contexto da inovação.

Os resultados dessa pesquisa são apresentados a seguir, no intuito de contribuir com as políticas públicas no contexto da inovaçáo das micro e pequenas empresas, iniciando-se com os fundamentos teóricos da inovação, descrevendo seus tipos e impactos que produzem. Na sequência são apresentadas as especificidades das empresas familiares. Em seção subsequente, apresentam-se os procedimentos metodológicos adotados no processo de coleta e análise dos dados, os resultados e as análises realizadas. Por fim são delineadas as conclusôes, com indicação das limitaçôes do estudo e sugestôes para pesquisas futuras.

\section{Revisão da literatura}

\subsection{Inovação}

O debate sobre inovação, como capacidade de criar novos valores em produtos/serviços, tem sua origem nos estudos de Schumpeter (1982), que enfatizou a inovação como um meio para alcançar o desenvolvimento econômico, pelo potencial em alterar o estado de equilíbrio de uma economia. Desde então a inovação passou a ser um fator importante para pensar o desenvolvimento das naçóes, e posteriormente seu escopo se ampliou para o desenvolvimento das organizações, bem como a formação de um ecossistema empreendedor que promove produtividade e desempenho (Silva, Rampasso, Anholon, Ordônez, Quelhas \& Silva, 2018).

Ao propor a criação de novos valores de mercado, a inovação, segundo Schumpeter (1982), caracteriza-se como a construçáo de uma nova combinaçáo produtiva mais eficaz do que a anterior, como fabricar um novo produto/serviço ou melhorar um já existente. O principal argumento teórico de Schumpeter (1982) está no desenvolvimento econômico guiado pela inovação por meio de um processo no qual as novas tecnologias substituem as antigas, cujo processo denominou "destruição criadora".

Além disso, Schumpeter (1982) divide as inovaçôes de acordo com a sua profundidade e intensidade, definindo-as em incrementais e radicais (disruptivas), as quais estão representadas na Figura 1, numa interpretação de Audy (2017). A inovação incremental envolve melhorias modestas em produtos/ serviços existente, enquanto as melhorias com rupturas estáo associadas à inovaçáo disruptiva. 
Figura 1 - Tipos de inovação e impactos que produzem
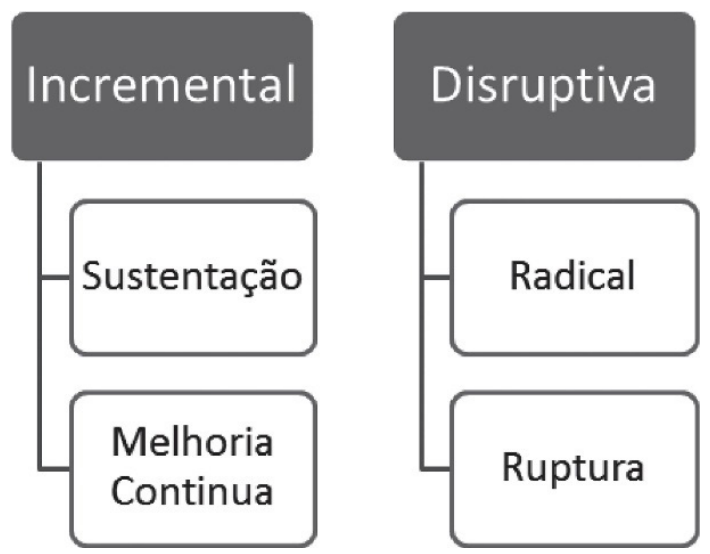

Fonte: De "A inovação, o desenvolvimento e o papel da universidade" de Audy, J. (2017), Estudos Avançados, 31(90), pp. 75-87.

Audy (2017) define a inovação incremental como sendo a geração de melhorias contínuas nas diferentes fases do ciclo de vida de produtos/processo, mas mantém o mesmo patamar tecnológico no qual se aplica. Barboza, Fonseca e Ramalheiro (2015) explicam que a inovação incremental é a inserção de mudanças em menor escala.

A inovação disruptiva, por sua vez, é aquela associada às mudanças radicais que posicionam produtos/ processos em um novo patamar tecnológico, indicando novas possibilidades de desenvolvimento, criando novas demandas e aplicaçóes. Estas inovaçóes geram rupturas mais intensas, ocasionando novas rotinas organizacionais, novos processos, novos produtos e novas ideias em relaçáo ao marketing do produto (Barboza et al., 2015). O impacto desta inovação radical pode mudar a estrutura de mercado ou tornar produtos existentes obsoletos. Todavia, pode não ser evidente se uma inovação é disruptiva no primeiro momento de sua introdução, o que pode dificultar a coleta de dados sobre inovaçóes disruptivas em determinado período de análise (OCDE, 1997).

Diante disso, a promoção de inovação como ação estratégica das empresas em busca do melhor desempenho no mercado vem se mostrando um importante alicerce de crescimento. Para tanto, as inovaçóes precisam ser valiosas, raras, difíceis de imitar (Scherer \& Carlomagno, 2016). A inovação associada à capacidade de aprender novos conteúdos e adaptar-se ao contexto do lugar podem representar fonte de vantagem competitiva pela qualidade nos produtos, pela eficiência do trabalho (Silva \& Dacorso, 2013), mas principalmente pela capacidade de modificar a natureza do produto ou serviço (Davies, Dodgson, \& Gann, 2016).

Conforme Crossan e Apaydin (2010, p. 1155), as definiçôes de inovação são inúmeras e podem enfatizar uma ideia diferente para o termo. Por isso definem inovação como sendo:

Produção ou adoção, assimilação e exploração de uma novidade de valor agregado nas esferas econômica e social; renovação e ampliação de produtos, serviços e mercados; desenvolvimento de novos métodos de produção; e estabelecimento de nova gestão sistemas. É tanto um processo quanto um resultado.

A inovação efetiva agrega valor ao produto, serviço ou processo (Audy, 2017), representa novas ideias ou ideias já existentes em determinado contexto. Esse é o mesmo entendimento presente no Manual 
de Oslo, publicado pela Organização para a Cooperação e Desenvolvimento Econômico (OCDE), o qual preconiza inovação como sendo a implementação de um produto (bem/serviço), método, processo organizacional ou técnica de marketing, novos ou significativamente melhorados, considerado um processo de geração de inovação e não somente um evento isolado e, pela sua heterogeneidade, permite desenvolver tipologias para desenvolver pesquisas específicas.

\subsection{Tipologia de Inovação}

Desde a proposição teórica de Schumpeter (1982) para a inovação, muito tem se discutido sobre o tema, inclusive com a categorização da inovaçáo de acordo com o impacto que ela provoca no desenvolvimento (econômico, organizacional, social). Uma importante referência para o entendimento dos tipos de inovação é o Manual de Oslo (OCDE, 1997).

O Manual de Oslo (OCDE, 1997) divide a inovação em quatro categorias, sendo elas: inovaçóes de produto, inovaçóes de processo, inovaçóes organizacionais e inovaçóes de marketing (Quadro 1). Embora as definiçóes relacionadas às áreas de produto sejam mais familiares às organizaçóes e ao setor de pesquisa (Barboza, Fonseca, \& Ramalheiro, 2015), as inovaçôes de processo, marketing e organização apresentam crescimento em razão da necessidade das empresas em criar e gerir conhecimentos próprios, os quais tem influência na performance organizacional.

Quadro 1 - Tipos de inovação

\begin{tabular}{|l|l|l|}
\hline Tipo de inovação & \multicolumn{1}{|c|}{ Definição } & \multicolumn{1}{c|}{ Exemplos } \\
\hline $\begin{array}{l}\text { Inovação de } \\
\text { produto }\end{array}$ & $\begin{array}{l}\text { Introdução de um bem ou serviço novo } \\
\text { ou significativamente melhorado no que } \\
\text { concerne a suas características ou usos } \\
\text { previstos. }\end{array}$ & $\begin{array}{l}\text { Implementação de melhorias significativos em } \\
\text { especificaçóes técnicas, componentes, softwares, } \\
\text { materiais ou outras características funcionais. } \\
\text { Pode-se incluir melhorias importantes na } \\
\text { forma de oferta ou na introduçáo de serviços } \\
\text { inteiramente novos. }\end{array}$ \\
\hline $\begin{array}{l}\text { Inovação de } \\
\text { processo }\end{array}$ & $\begin{array}{l}\text { Implementação de um método de } \\
\text { produção ou distribuição novo ou } \\
\text { significativamente melhorado. }\end{array}$ & $\begin{array}{l}\text { Implantação de técnicas, equipamentos e } \\
\text { softwares na área produtiva, além de novas formas } \\
\text { de fornecer e alocar suprimentos em relaçáo à } \\
\text { logística da empresa. }\end{array}$ \\
\hline $\begin{array}{l}\text { Inovação de } \\
\text { marketing }\end{array}$ & $\begin{array}{l}\text { Implementação de novo método de } \\
\text { marketing com mudanças significativas na } \\
\text { concepção do produto ou na embalagem, } \\
\text { posicionamento do produto, promoção } \\
\text { ou na fixação de preços. }\end{array}$ & $\begin{array}{l}\text { Mudanças substanciais no design (forma e } \\
\text { aparência) do produto, introdução de novos } \\
\text { canais de vendas, novos conceitos para promover } \\
\text { bens ou serviços e novas estratégias de fixação de } \\
\text { preços para comercialização. }\end{array}$ \\
\hline $\begin{array}{l}\text { Inovação } \\
\text { organizacional }\end{array}$ & $\begin{array}{l}\text { Compreendem a implementação de novas } \\
\text { práticas de negócios para a organização de } \\
\text { rotinas e procedimentos para a condução } \\
\text { do trabalho. }\end{array}$ & $\begin{array}{l}\text { Implementação de um novo método } \\
\text { organizacional nas práticas de negócios, na } \\
\text { organizaçáo do ambiente de trabalho ou nas } \\
\text { relaçóes externas. }\end{array}$ \\
\hline
\end{tabular}

Fonte: Adaptado de OCDE (1997). 
Uma empresa pode promover diversos tipos de mudanças em seus métodos de trabalho, em sua produçâo e em seu desempenho comercial. Contudo, para uma mudança ser classificada inovação precisa demonstrar um grau notável de novidade, não necessariamente ser desenvolvida pela própria empresa, mas que agregue valor (Audy, 2017; OCDE, 1997). No entanto, há de se considerar que a singularidade do porte e o tipo de propriedade das empresas apresentam relação positiva com a forma em que as novidades são geradas (Barboza et al., 2015), em especial na empresa familiar, pelo sentimento de compromisso do fundador e dos membros de sua família (Alves \& Gama, 2020).

\subsection{Empresa Familiar}

Forma predominante em todo o mundo, as empresas familiares despertam crescente interesse entre pesquisadores no campo da estratégia (Andersén, 2015; De Massis; Di Minin, \& Frattini, 2015; Daspit, Long, \& Pearson, 2018; Payne, 2020). Apesar do avanço dos estudos relacionados à empresa familiar, sua definição não é consensual e uma abordagem configuracional seria especialmente útil para examinar sua heterogeneidade, no entendimento de Neubaum, Kammerlander e Brigham (2019).

Payne (2020) reconhece que as questôes de tempo, velocidade das mudanças no contexto, tipos de inovação e flexibilidade organizacional estão entre as questôes mais importantes para as empresas de hoje. Contudo, afirma o autor, ainda há muitas questóes que precisam ser revisadas nos estudos sobre empresas familiares. Entre outros, Neubaum et al. (2019) e Alves e Gama (2020) apontam a sua heterogeneidade e a influência que a mudança na família produz na gestão e na sua performance, além do elevado apego emocional entre os membros da família (Qiu \& Freel, 2020), as limitaçóes operacionais e estratégicas na implementação de inovação disruptiva em diferentes fases do seu ciclo de vida.

A concepção de inovação com capacidades organizacionais está em Audy (2017, p. 75), quando afirma que inovador é quem tem "capacidade de transformar o mundo a seu redor, agregar valor" (econômico, social, pessoal) e transformar ou criar o novo. Nesse sentido, a inovação pode ser diferente em empresas familiares e não familiares (Padilla-Meléndez et al., 2015). A complexidade das três dimensôes (propriedade, gestão e família) da empresa familiar, seu comportamento e forças distintas podem gerar oportunidades de inovação, pela facilidade de transmissão de informaçôes, relaçôes sociais entre familiares na gestão e orientação estratégica (Alves \& Gama, 2020). Contudo, a resistência de seus membros em favor da inovação potencial pode representar um paradoxo na empresa familiar (De Massis et al., 2015).

Soma-se a estes aspectos, o fato de MPEFs dependerem fortemente da geração de inovação para sobreviverem (Silva et al., 2018). Contudo, possuem problemas de gestão e recursos financeiros limitados para gerar inovação (Silva \& Dacorso, 2016). Admite-se que o grau de heterogeneidade entre as empresas familiares é crescente e gera discordância entre os pesquisadores (Chua, Chrismanm, Steier, \& Lau, 2012) sobre definiçôes e, por conseguinte, afirmaçóes com maior grau de certeza.

No que se refere à tipologia, o principal critério adotado nas pesquisas brasileiras é classificação relacionada às geraçóes de membros da família empresária que atuam na empresa. Apoiando-se em Gersick et al. (1997), pode-se considerar as empresas familiares como sendo de primeira geraçáo quando ela é de propriedade da família e continua dirigida pelo(s) fundador(es), mas também é considerada familiar quando algum membro da geração seguinte desempenha nela algum tipo de função na direção. 
A empresa de segunda geraçáo é classificada desta forma quando o fundador, caso esteja vivo, passou para um segundo plano de gestão e o controle passou para seus filhos ou sobrinhos, enquanto as empresas familiares de terceira geraçáo ou posteriores são empresas familiares em que os netos, bisnetos e assim sucessivamente do fundador são os principais proprietários ou gestores.

\section{Procedimentos metodológicos}

Trata-se de uma pesquisa social aplicada, do tipo levantamento (Hair, Babin, Samouel, \& Money, 2007), com abordagem quantitativa dos dados. O universo da pesquisa (1647 empresas) foi determinado pelo número de ME (1558 empresas) e de EPP (89 empresas) existentes em Marau, município localizado no estado do Rio Grande do Sul. Para tanto tomou-se os conceitos de porte de empresas presente na Lei Complementar no 123 (Brasil, 2006) e o Relatório do Rol Cadastral Simplificado do Mobiliário disponibilizado pela Prefeitura Municipal de Marau (2018). Com base em Barbetta (2002), a amostra foi calculada considerando a populaçáo finita, erro amostral de 10\% e nível de confiança de 90\%, considerando o valor de amostragem de, no mínimo, 66 empresas microempresas (ME) e empresas de pequeno porte $(\mathrm{EPP})$ - válidas somente empresas de propriedade e gestão familiar.

Os sujeitos da pesquisa são, em sua maioria, casados, na faixa etária entre 22 e 34 anos (41\%), com grau de escolaridade de terceiro grau superior ou acima (66\%). Por se tratar de proprietários de empresas de MPEFs, os respondentes se auto definem como ocupantes de cargos de gerente/diretor/administrador (96\%). Outras se auto definem pela sua profissão, como esteticista, agrônoma e arquiteto, em razão de serem profissionais habilitados que realizam trabalhos técnicos na área desta habilitação na empresa que constituíram.

Os dados foram coletados por meio de questionários auto administrados, entregue de forma presencial e impressa, para medir características das empresas e proprietários por meio de um conjunto predeterminado de perguntas (Hair et al., 2007). O questionário foi desenvolvido com base do Manual de Oslo (OCDE, 1997) e no relatório "Pesquisa de Inovação (Pintec)", editado pelo Instituto Brasileiro de Geografia e Estatística (IBGE) em 2014, o qual fornece informaçóes acerca das atividades de inovação empreendidas pelas empresas brasileiras.

O questionário foi estruturado em duas partes, sendo a primeira sessão de perguntas elaboradas com vistas a investigar: (a) o empreendimento quanto ao porte, tipo de propriedade, tempo de existência, segmento de atuação e ramo de atividade; (b) características do perfil do respondente, como cargo, tempo de atuação na empresa, relação de parentesco com o fundador, idade, gênero, nível instrucional e área de formação àqueles com grau de instrução superior. A segunda sessão de perguntas foi elaborada para mapear os conteúdos específicos do estudo, os quais são: implementação de inovação de produto para a empresa e/ou para o mercado, de processo para a empresa e/ou para o mercado, bem como inovação de marketing e organizacional, fontes de financiamentos utilizadas para inserção da inovação, os impactos e os desafios da inovação.

A primeira versão do questionário foi submetida a um pré-teste para validação das questôes em empresas de outro município. Após ajustes na redação e na estrutura das questóes, o questionário foi aplicado às empresas da amostra. Os dados obtidos foram tabulados utilizando o software Statistical Package For Social 
(SPSS ${ }^{\oplus)}$, Versão 22.0. O processo de análise dos dados foi orientado pela abordagem quantitativa (Hair $e t$ al., 2007), de acordo com o método de análise estatística descritiva, com vistas a calcular a frequência das respostas, o desvio padrão, a média e a variância, a qual confere confiabilidade às análises.

\section{Análise de resultados}

\subsection{Caracterização da amostra}

Os resultados do estudo indicam predominância de MPEFs marauenses atuando como empresas comerciais $(57,00 \%)$, seguidas por prestadoras de serviços $(36,00 \%)$ e industriais $(7,00 \%)$. Conforme consta na Tabela 1 , a maioria dos respondentes (59,70\%) ingressou na empresa por ser filho ou parente do proprietário; 40,30\% daqueles que são membros da família empresária ingressaram por terem qualificação profissional.

Tabela 1 - Razão do ingresso de membros da família

\begin{tabular}{|l|c|c|}
\hline \multicolumn{1}{|c|}{ Resposta } & Frequência & \% \\
\hline São profissionais altamente qualificados na função que a empresa precisava & 27 & 40,30 \\
\hline São filhos ou parentes do dono & 40 & 59,70 \\
\hline Total & $\mathbf{6 7}$ & 100,00 \\
\hline
\end{tabular}

Fonte: Dados de pesquisa (2019).

Ao mesmo tempo em que os membros da família assumem a gestão da empresa para dar continuidade ao empreendimento familiar, idealizado pelos membros da geração anterior, também se referem à empresa como sendo um espaço para ingressar no mercado de trabalho mesmo sem ter experiência. Tal resultado remete o debate teórico para a cultura do compromisso descrita por Alves e Gama (2020), vinculando os objetivos de perpetuidade e de conservação do patrimônio familiar e objetivos não-financeiros, como o de inserção dos familiares no mercado de trabalho.

Conforme Tabela 2, as empresas participantes do estudo são familiares e a maioria (49,25\%) encontra-se na segunda geração de membros da família, sendo gerenciada pelos filhos dos fundadores. A análise cumulativa dos dados revela que $88,06 \%$ das MPEFs estấo na primeira ou segunda geraçáo dos membros da família empresária.

Tabela 2 - Classificação de acordo com a geração que está na empresa

\begin{tabular}{lccc}
\hline \multicolumn{1}{c}{ Resposta } & Frequência & $\begin{array}{c}\text { Porcentagem } \\
\text { (\%) }\end{array}$ & $\begin{array}{c}\text { Porcentagem } \\
\text { acumulada }\end{array}$ \\
\hline 1 a geração (Fundador) & 26 & 38,81 & 38,81 \\
\hline 2a geração (Filhos do fundador) & 33 & 49,25 & 88,06 \\
\hline 3a geração (Netos do fundador) & 7 & 10,45 & 98,51 \\
\hline 4a geraçáa (Bisnetos do fundador) & 1 & 1,49 & 100,00 \\
\hline Total & $\mathbf{6 7}$ & $\mathbf{1 0 0 , 0 0}$ & \\
\hline
\end{tabular}

Fonte: Dados de pesquisa (2019). 
Com base em Gersick et al. (1997), isso significa dizer que que o fundador permanece ativo na gestão dos negócios, mas há convivência intergeracional pela presença de filhos do fundador em cargos de gestão; alguns deles podem ter assumido a gestáo dos negócios, mesmo que seus pais ainda estejam realizando atividades operacionais na empresa que fundaram.

A constatação de que a maioria das empresas investigadas se encontram nas duas primeiras geraçóes de membros das famílias proprietários representa um momento de preocupação com o seu futuro. Gersick et al. (1997) consideram esse um momento crítico no ciclo de vida de empresas familiares em geral, em razão da eminência do ingresso dos membros da terceira geração, determinado pela ocorrência do maior índice de mortalidade empresarial. Os conflitos relacionados à família empresária (Qiu \& Freel, 2020), os aspectos obscuros de alguns atributos da família nos negócios familiares (Combs \& Shanine, 2020) e a influência da família na performance da empresa (Alves \& Gama, 2020) indicam que o momento exige do gestor a realização de açôes inovativas com maior grau de risco.

\subsection{Inovação nas micro e pequenas empresas marauenses}

O relatório da OCDE (1997) indica a implementação de sistemas formais de gerenciamento de produto e mercado, bem como de sistemas estruturados para orientar o processo decisório com base em controles de gestão, uma possibilidade de superação deste estágio crítico. Trata-se de um tipo de inovação, a inovação organizacional.

No intuito de compreender a visão do empreendedor acerca do grau de inovação na sua empresa (PINTEC, 2014), a Tabela 3 apresenta a opinião de 49,25\% dos respondentes que consideram as suas empresas modernas e altamente inovadoras. Todos concordam que as inovaçóes apresentam impactos organizacionais positivos.

Tabela 3 - Visão dos respondentes acerca do grau de inovação da empresa

\begin{tabular}{lcr}
\hline \multicolumn{1}{c}{ Resposta } & Frequência & \% \\
\hline Moderna, mas gera pouca inovação & 14 & 20,90 \\
\hline Moderna e é altamente inovadora & 33 & 49,25 \\
\hline Faz um produto de alta qualidade, mas não é moderna nem inovadora & 10 & 14,93 \\
\hline $\begin{array}{l}\text { Faz apenas o básico para manter a atividade como uma fonte de renda e } \\
\text { atender bem os clientes, com qualidade }\end{array}$ & 10 & 14,93 \\
\hline Total & $\mathbf{6 7}$ & $\mathbf{1 0 0 , 0 0}$ \\
\hline
\end{tabular}

Fonte: Dados de pesquisa (2019).

A forma pela qual os gestores percebem os impactos das inovaçóes se mostra favorável ao desenvolvimento de mudanças significativas, ressalvando que isso não necessariamente ocorre. No Brasil, o contexto de inovação passou por mudanças (Campos \& Campos, 2013) decorrentes da regulamentaçáo da lei da inovação (Brasil, 2004) e da criação de fundos públicos de incentivo à inovação (Brasil, 2004) com vistas à pesquisa e capacitação tecnológica.

Conforme Tabela 4, a maior porcentagem dos recursos, utilizados para financiamento das atividades de inovação, é próprio; apenas 8,96\% das empresas utilizam de linhas de crédito disponibilizadas por 
instituições financeiras privadas. $\mathrm{O}$ uso dos recursos ofertados pela Financiadora de Estudos e Projetos (FINEP) e pelo Banco Nacional de Desenvolvimento Econômico e Social (BNDES) é realizado por apenas 2,99\% das empresas investigadas.

Tabela 4 - Financiamento das atividades de inovação

\begin{tabular}{lcr}
\hline \multicolumn{1}{c}{ Resposta } & Frequência & \% \\
\hline Fundos próprios da empresa & 59 & 88,06 \\
\hline Empréstimos em Instituiçóes Financeiras privadas & 6 & 8,96 \\
\hline Empréstimos em Instituiçóes Financeiras públicas (Finep, BNDES...) & 2 & 2,99 \\
\hline Instituiçóes de pesquisa, centros tecnológicos e/ou universidades privadas & 0 & 0,00 \\
\hline Instituiçóes de pesquisa, centros tecnológicos e/ou universidades públicas & 0 & 0,00 \\
\hline Procedente do exterior & 0 & 0,00 \\
\hline Total & $\mathbf{6 7}$ & $\mathbf{1 0 0 , 0 0}$ \\
\hline
\end{tabular}

Fonte: Dados de pesquisa (2019).

As empresas que declararam dificuldades na implementação de determinadas atividades de inovação representam 67,00\%. Estudos desenvolvidos por Nogueira (2017) mostram que as açóes públicas de promoção de inovaçáo por muitas vezes são menosprezadas pelas pequenas empresas, por baixa produtividade ou reduzida capacidade absortiva.

Quando questionados sobre o que limita a geração de inovaçôes em suas organizaçôes, as MPEFs apontaram elevados custos de inovação, os riscos econômicos envolvidos nos processos e falta de pessoal qualificado, como consta na Tabela 5.

Tabela 5 - Fatores que impossibilitam ou inviabilizam a geração de inovação

\begin{tabular}{|c|c|c|}
\hline Resposta & Frequência & $\%$ \\
\hline Riscos econômicos excessivos & 31 & 22,30 \\
\hline Elevados custos de inovação & 34 & 24,46 \\
\hline Escassez de fontes apropriadas de financiamento & 2 & 1,44 \\
\hline Rigidez organizacional & 6 & 4,32 \\
\hline Falta de pessoal qualificado & 21 & 15,11 \\
\hline Falta de informação sobre tecnologia & 7 & 5,04 \\
\hline Falta de informação sobre mercado & 6 & 4,32 \\
\hline Escassas possibilidades de cooperação com outras empresas/instituiçôes & 4 & 2,88 \\
\hline Dificuldade para se adequar a padróes, normas e regulamentaçóes & 10 & 7,19 \\
\hline Fraca resposta dos consumidores quanto a novidades & 12 & 8,63 \\
\hline Escassez de serviços técnicos adequados & 6 & 4,32 \\
\hline Total & 139 & 100,00 \\
\hline
\end{tabular}

Fonte: Dados de pesquisa (2019). 
Tais resultados validam as afirmaçôes de Silva, Botelho e Rodrigues (2016) quanto às dificuldades de amortização dos investimentos em inovação realizados por pequenas empresas. Os respondentes afirmam que grandes empresas têm facilidades na obtenção de recursos, acesso facilitado às linhas de crédito, capacidade de lidar com os riscos financeiros dos projetos, além de possuir recursos humanos qualificado quando comparadas às empresas de menor porte. Pereira, Grappegia, Emmendoerfer e Três (2009) e Nogueira (2017) afirmam que essa é a realidade no contexto brasileiro, dando suporte às percepçóes dos empresários.

Os respondentes percebem também que, em razão de suas empresas serem micro ou de pequeno porte, têm mais flexibilidade organizacional facilidade de transmissão de informaçôes de valor à equipe de trabalho, processo de integração entre os membros da equipe de trabalho e orientação de longo prazo. Nogueira (2017) considera esses aspectos de flexibilidade organizacional para gerar oportunidades de criaçáo de inovaçáo. Apenas 4,32\% dos respondentes entendem que os processos de trabalho rígidos e que essa estrutura organizacional limita a capacidade de a empresa gerar inovação.

As empresas familiares que afirmam não terem enfrentado dificuldades em implementar atividades de inovação $(33,00 \%)$ são de pequeno porte $(72,70 \%)$ e estão em processo de transição da primeira para a segunda geração de membros da família. Em 31,82\% das empresas pesquisadas, a inovação de produto representa um bem completamente novo para a empresa ou para o mercado. A principal inovação gerada pelas MPEFs foi no processo (63,64\%). No caso da inovação de marketing e organizacional, 22,70\% das empresas não inseriram melhorias significativas e $18,18 \%$ não realizaram inovação nos processos organizacionais.

A respeito, Nogueira (2017) afirma que que as pequenas empresas lançaram quatro vezes menos produtos novos para o mercado brasileiro, tendo como principal justificativa a dificuldade para aquisição de direitos de propriedade intelectual e de origem de capital para sustentar açôes de pesquisa e desenvolvimento (P\&D).

Os dados coletados evidenciam uma característica importante dessas empresas. O proprietário da MPEFs é o responsável pela condução do processo de inovação. Tais achados confirmam as afirmaçóes de Frank et al. (2019) sobre as particularidades do processo de inovação nas empresas familiares. Embora MPEFs invistam menos em $\mathrm{P} \& \mathrm{D}$, os resultados da inovaçáo refletem o papel exercido pelo empreendedor, no sentido descrito por Ter Wal et al. (2017). A visão empreendedora encontra-se descrita nos fundamentos clássicos da inovação. Schumpeter (1982) sustenta que a figura do empreendedor é central no processo inovativo.

Conforme Tabela 6, no processo de inovação nas MPEFs investigadas, somam-se ao empreendedor os membros da família e os funcionários. Juntos constituem uma "equipe de trabalho" em prol da inovação, principalmente em inovaçáo de produto. 
Tabela 6 - Responsáveis pelo desenvolvimento das inovaçóes nas pequenas empresas.

\begin{tabular}{|l|c|c|c|c|}
\hline Características dos responsáveis pela inovaçáa & Produto & Processo & Marketing & Organizacional \\
\hline O proprietário da empresa & 42 & 34 & 25 & 36 \\
\hline $\begin{array}{l}\text { Os funcionários, que se reuniram espontaneamente e } \\
\text { desenvolveram uma ideia }\end{array}$ & 7 & 8 & 3 & 8 \\
\hline $\begin{array}{l}\text { A equipe de trabalho designada pela empresa e em parceria } \\
\text { com outras empresas/fornecedores }\end{array}$ & 20 & 13 & 14 & 13 \\
\hline $\begin{array}{l}\text { A empresa, em parceria com uma universidade/centro de } \\
\text { pesquisa }\end{array}$ & 1 & 0 & 2 & 3 \\
\hline As empresas prestadoras de serviço para a minha empresa & 6 & 6 & 1 & 4 \\
\hline
\end{tabular}

Fonte: Dados de pesquisa (2019).

Tal dinâmica e condução do processo de inovação nas MPEFs marauenses, envolvendo todos numa estrutura flexível de decisão e orientada pelo proprietário, indica que não existe um processo de P\&D estruturado. A OCDE (1997, p. 35) confirma teoricamente tais achados, quando declara: "muitas atividades inovadoras não são baseadas em $\mathrm{P} \& \mathrm{D}$, ainda que elas dependam de trabalhadores altamente capacitados, interaçôes com outras empresas e instituições públicas de pesquisa e uma estrutura organizacional que conduz ao aprendizado e à exploração do conhecimento”.

É praticamente nula a parceria de universidades e centros de pesquisas para geração de inovação com as MPEFs analisadas. Nogueira (2017) e Campos e Campos (2013) corroboram tais achados ao afirmarem que há menor propensáo de pequenas empresas estabelecerem parcerias e aderirem à projetos de inovação comparativamente às grandes empresas.

A postura adotada pelas empresas familiares em relação ao processo inovativo incremental influencia diretamente a sua sobrevivência no setor em que atuam. Contudo, assim como qualquer outra, na empresa familiar é necessária inovação disruptiva em razão da demanda do contexto por desenvolvimentos de capacidades organizacionais, para se diferenciar no mercado ao mesmo tempo em que se reinventa durante o processo de transição geracional.

A inovação, que representa um fator de sobrevivência para as micro e pequenas, pode representar um diferencial de mercado e uma competição menos desigual no mundo dos negócios quando os recursos escassos são utilizados adequadamente. Em Marau, verificou-se que 13,00\% das empresas deste estrato não introduziram bem ou serviço novo, ou significativamente melhorado, mas que a maioria (87,00\%) realizou inovaçôes em produto.

Ao considerar o grau de inovação de produto, 56,00\% das MPEFs realizam aprimoramento em um bem ou serviço já produzido pela empresa. Conforme mostra a Figura 2, a inovação que gerou um produto completamente novo para a empresa representa 39,00\%, enquanto apenas 5,00\% lançaram produto considerado novo no mercado de atuaçáo. 
Figura 2 - Grau de inovação de produto

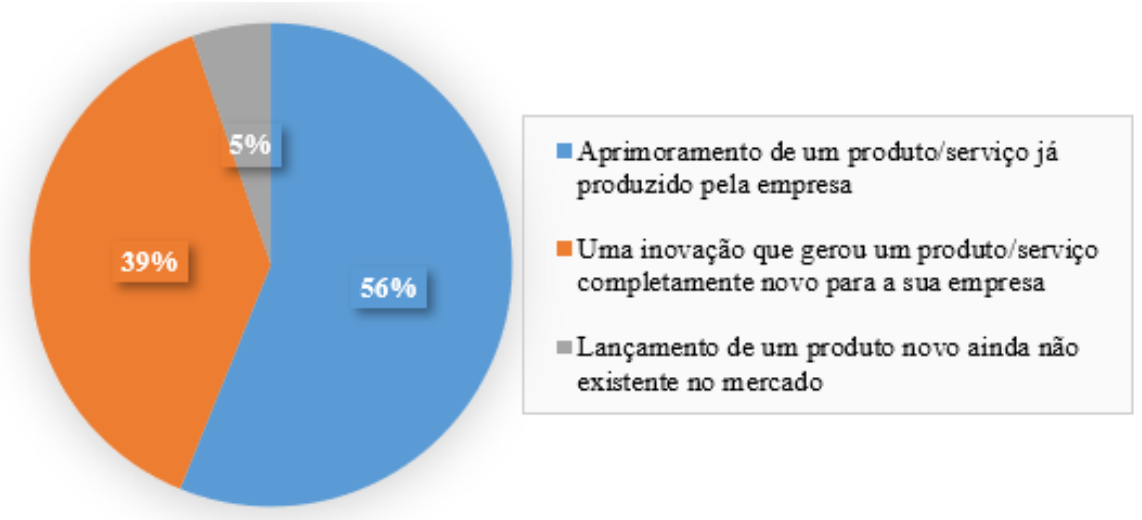

Fonte: Dados de pesquisa (2019).

Tais resultados da inovação nas MPEFs marauenses indicam que a maioria das inovaçôes de produto implementadas são incrementais, as quais refletem os resultados de outras empresas brasileiras descritas no Pintec (2014). Nas empresas brasileiras, as atividades de $\mathrm{P} \& \mathrm{D}$ não possuem uma estrutura formal, acarretando redução do número de inovações radicais ou disruptivas (PINTEC, 2014).

A inovação de processo corresponde a implantação de um método de produção novo ou substancialmente melhorado (OCDE, 1997). Os métodos de produção envolvem as técnicas, equipamentos e softwares utilizados para produção de bens ou serviços, sendo que $14,00 \%$ das empresas investigadas não introduziram nenhuma melhoria em seus processos (Figura 3). Contudo, quando as empresas implementam inovaçôes de processo, a maioria ocorre no método ou na técnica utilizada para a produção dos bens ou na prestação de serviços.

Figura 3 - Implementação de inovação de processo

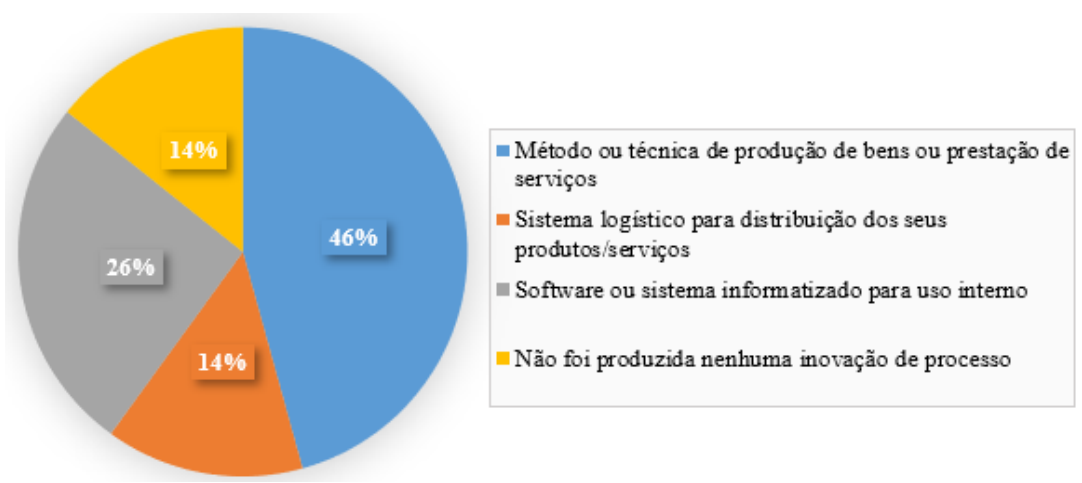

Fonte: Dados de pesquisa (2019).

Cabe pontuar que no caso em que não foram geradas inovação de processos, em 60,00\% a relação de parentesco é intergeracional e também prestadora de serviço, mas que introduziram inovaçóes de produto, de marketing e organizacional. No que concerne ao grau de inovação de processo das empresas, é possível identificar que as melhorias e novidades são inovaçôes para a empresa $(73,00 \%)$, pois já existem no mercado.

A inovação de marketing é a implementação de um novo método de marketing com mudanças significativas na concepçáo do produto ou na embalagem, no posicionamento do produto, na promoção ou na fixação de preços (OCDE, 1997). Quando questionados se foi introduzida alguma técnica de marketing 
nova ou significativamente melhorada nos últimos 5 anos, 42,00\% dos respondentes afirmam que ocorreu inovação no posicionamento do bem ou serviço, contudo $21,00 \%$ afirmam que não introduziram nenhuma inovação em marketing, como pode-se observar nos dados apresentados na Figura 4.

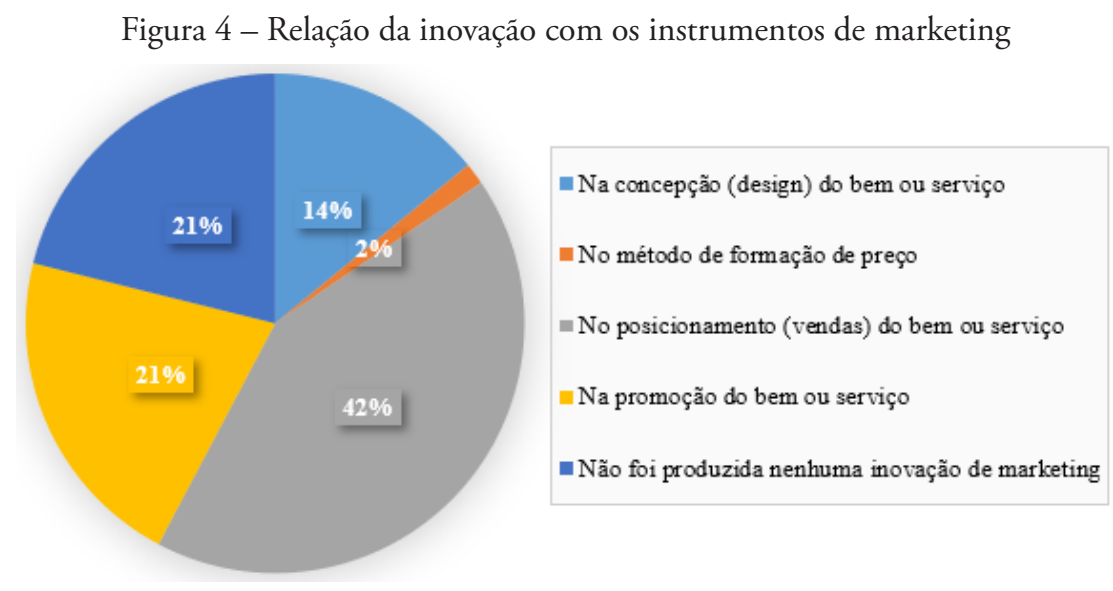

Fonte: Dados de pesquisa (2019).

Com relação às novas ou significativamente melhoradas práticas organizacionais, ao contrário do que se observou na inovação em marketing, $82,00 \%$ das empresas implementaram inovaçóes nos últimos cinco anos. A respeito, apoiando-se nas orientaçôes da OCDE (1997), inovação organizacional refere-se à implementação de um novo método organizacional nas práticas de negócios da empresa, na organização do seu local de trabalho ou em suas relaçôes externas que não tenha sido usado anteriormente na empresa e que seja o resultado de decisóes estratégicas tomadas pelos gestores. Nesse sentido, o fato das inovaçóes em marketing não serem contempladas nas práticas organizacionais pode indicar que há uma preocupação do empresário mais para o ambiente interno da empresa do que um olhar mais crítico sobre o mercado, mudanças em curso na sociedade e/ou no perfil dos consumidores.

Com vistas a aprofundar esta questão específica da inovação organizacional, os empresários foram questionados a respeito de qual técnica organizacional ocorreu inovação no período de análise. Conforme figura 5, em 46\% dos casos, a inovação ocorreu na condução do trabalho, ou seja, nas práticas de negócios para reorganizar rotinas e procedimentos. Tal dado confirma a impressão descrita anteriormente, de um olhar mais voltado para o ambiente interno do que para o mercado (ambiente externo).

Figura 5 - Implementação de inovação nos métodos organizacionais

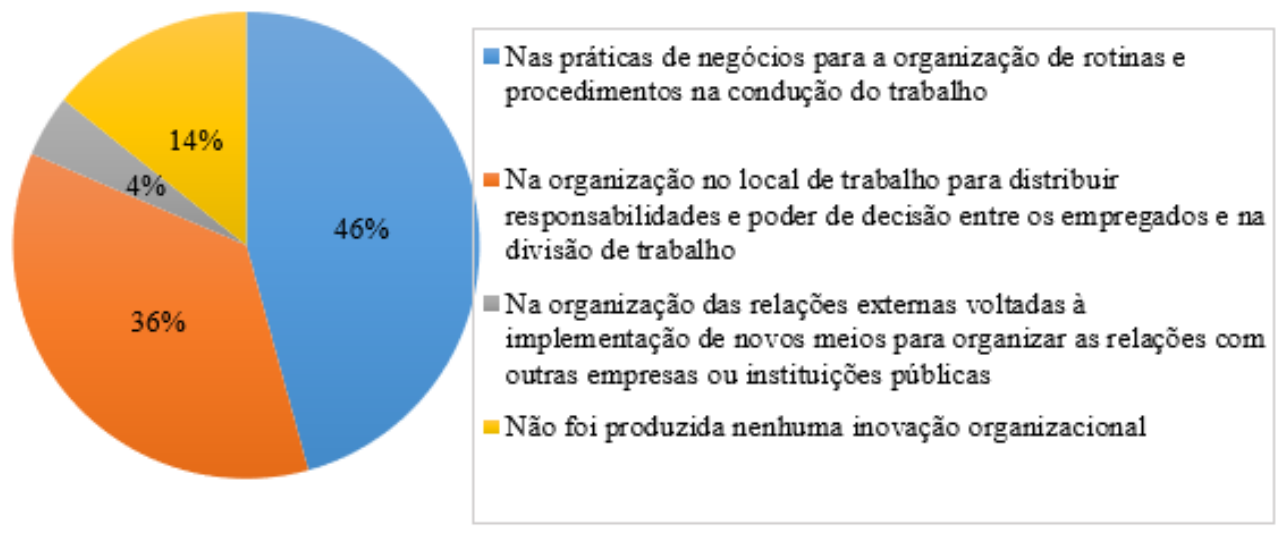

Fonte: Dados de pesquisa (2019). 
Ao analisar os dados com base na tipologia da inovação apresentada pelo Manual de Oslo (OCDE, 1997), constata-se que a inovação em produto é a mais representativa (61\%), seguida pela inovação em processo $(60 \%)$, inovação organizacional $(53 \%)$ e, por último, inovaçáo de marketing (48\%).

Conforme representado graficamente na Figura 6 e corroborando com os achados de Dalla Corte e Waquill (2015) e Nogueira (2017), as MPEs priorizam o lançamento de novos produtos e a modernização dos processos, dispóem recursos para produzir/implementar inovaçóes organizacionais, mas a inovação de marketing é considerada de menor importância.

Figura 6 - Frequência por tipo de inovação

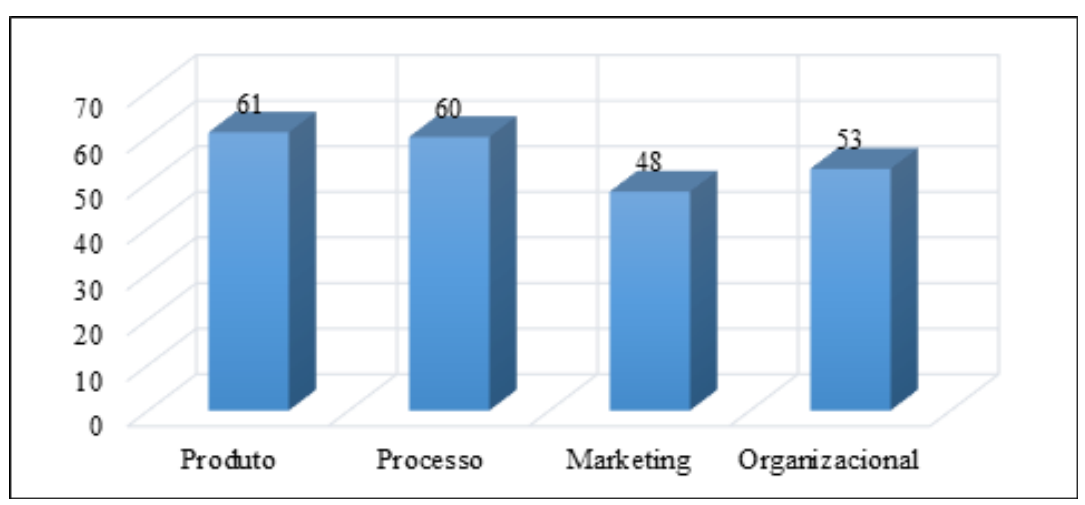

Fonte: Dados de pesquisa (2019).

O porte das empresas influencia no nível de geração de inovação (PINTEC, 2014). Da mesma forma, o setor em que atuam também influencia o tipo de inovação que produzem (Nogueira, 2017). Nas empresas marauenses se observou esta mesma dinâmica da inovaçáo, à qual se inclui ao porte e ao setor de atuação a geração de membros da família proprietária.

A decisão de inovar envolve certos riscos e incertezas, principalmente no caso das microempresas e empresas de pequeno porte. Desta forma, faz-se necessário entender quais fatores levam as empresas a gerarem inovação em seu âmbito empresarial. Conforme Tabela 7, para 21,62\% das organizaçôes o principal fator para geração de inovação é a necessidade.

Tabela 7 - Fatores que influenciam a empresa a gerar inovação

\begin{tabular}{lcr}
\hline \multicolumn{1}{c}{ FATORES INFLUENCIADORES DE INOVAÇÁO } & N & \% \\
\hline Oportunidade & 29 & 15,68 \\
\hline Necessidade & 40 & 21,62 \\
\hline Eficiência & 26 & 14,05 \\
\hline Qualidade & 37 & 20,00 \\
\hline Capacidade de aprendizagem & 6 & 3,24 \\
\hline Desempenho no mercado & 26 & 14,05 \\
\hline Lucros & 21 & 11,35 \\
\hline Total & $\mathbf{1 8 5}$ & 100,00 \\
\hline
\end{tabular}

Fonte: Dados da Pesquisa (2019). 
Silva e Dacorso (2014) explicam os resultados. As empresas sentem necessidade de gerar inovação por demanda de mercado, seja por atuarem em ambiente altamente competitivo e ter recursos escassos ou por estarem em busca de desempenhos organizacionais distintos. Soma-se à necessidade a qualidade $(20,00 \%)$, oportunidade $(15,68 \%)$ e eficiência $(14,05 \%)$ como fatores importantes para a geração de inovação das empresas investigadas.

Além das análises de frequência que caracterizam a estatística descritiva simples, os dados foram submetidos à análise estatística descritiva mais robusta, com vistas a obter maior confiabilidade dos dados. Então foram calculados média, desvio padrão e variância das variáveis de inovação, cujos resultados estão dispostos na Tabela 8.

Tabela 8 - Análise estatística da inovação

\begin{tabular}{|c|l|r|r|r|}
\hline Grupos & \multicolumn{1}{|c|}{ Variáveis } & \multicolumn{1}{c|}{ Média } & \multicolumn{1}{c|}{ Desvio Padrão } & \multicolumn{1}{c|}{ Variância } \\
\hline 1 & Novo produto & 1,09 & 0,288 & 0,083 \\
\hline 2 & Inovação de produto & 1,13 & 0,344 & 0,118 \\
\hline 3 & Inovação de processo & 2,45 & 1,480 & 2,190 \\
\hline 4 & Inovação de marketing & 1,22 & 0,487 & 0,237 \\
\hline 5 & Inovação organizacional & 1,15 & 0,435 & 0,190 \\
\hline 6 & Método organizacional & 2,09 & 1,443 & 2,083 \\
\hline
\end{tabular}

Fonte: As autoras (2019).

As variáveis trabalhadas estatisticamente são: (1) novo produto, (2) inovação em produto, (3) inovação de processo, (4) inovação de marketing, (5) inovação organizacional e (6) método organizacional, colaborando para atingir o objetivo proposto no estudo. Mediante isso, procurando relacionar os resultados alcançados da estatística descritiva com a frequência simples dos dados, podem ser inferidos: os grupos 3 e 6 que apresentaram, se comparados com o grupo 1,2 , 4 e 5 médias superiores $(2,45 ; 2,09)$ e maior dispersão dos dados.

A variabilidade das médias entre grupos apresentou-se elevada, porém, as dispersões dos dados foram mais comportadas nas suas diferenças. Apesar das redundâncias e dos questionamentos relacionados aos constructos e de seus respectivos grupos, pode-se dizer que os resultados conferem robustez e consistência teórica.

\section{Conclusões}

A postura estratégica adotada pelas empresas familiares de micro e pequeno porte em relação ao processo inovativo influencia diretamente a competitividade e a sobrevivência das organizaçóes no setor em que atuam. Este modelo de gestão peculiar, ligado intrinsecamente à história, identidade e linguagem do empreendedor e de sua família, resulta em decisóes importantes acerca da geração - ou não - das inovaçôes como prática de reação às ações do mercado e se reinventando ao longo do processo cíclico. A complexidade na geração de inovação em razão do porte (Frank et al., 2019), a ausência/limitação de recursos para sustentar o próprio empreendimento (Alves \& Gama, 2020; Kammerlander \& Breugst, 2019) e a influência da família proprietária na empresa (Gersick et al., 1997; Alves \& Gama, 2020) são 
apenas alguns dos aspectos a considerar. Assim, este modelo de gestão peculiar, ligado intrinsecamente com a história, identidade e linguagem do empreendedor e de sua família, influencia na geração de inovação radical e incremental da empresa.

Os dados revelam que as empresas familiares geram inovação incremental, ou seja, melhorias em seu ciclo de produtos, processos, de marketing e organizacional, mantendo o mesmo patamar, com mudanças em menor escala identificadas por Audy (2017). As inovaçóes ocorrem em processos informais, tendo em vista que não há grupos de trabalho responsáveis pela $\mathrm{P} \& \mathrm{D}$. O sistema administrativo fracamente estruturado contribui para a interaçáo social e o estabelecimento de laços afetivos entre empreendedor, membros de sua família e funcionários. A estrutura organizacional flexível é considerada pelos respondentes como adequada para o porte da empresa, pois agiliza o processo decisório e reduz o número de pessoas na realização das atividades. Em contrapartida, não há práticas de interação com outras empresas e/ ou universidades com vistas a geração de inovação disruptiva, num processo colaborativo com vistas a superação da limitação de acesso a recursos de valor.

A percepção dos respondentes de que os fatores de natureza econômica (riscos econômicos excessivos e os elevados custos de inovação) são os principais obstáculos para gerar inovação, corroboram com dados descritos no Pintec (2014) sobre o processo de inovação em nível de Brasil. Àquelas empresas que geram alguma inovação, o fazem por necessidade, como apontam Reichert, Camboim e Zawislak (2015). A inovação, em algumas empresas, é marcada pela manutenção da qualidade de produtos/serviços/processo e de uma postura passiva no mercado (Reichert, Camboim, \& Zawislak, 2015).

Há possibilidades de estudos futuros sobre o tema utilizando-se abordagens teórico-metodológicas para além do Manual de Oslo para estudos de inovação em micro e pequenas empresas familiares. Uma sugestão é aprofundar os estudos utilizando os fundamentos teóricos da capacidade absortiva para refletir sobre o papel do empreendedor na geração da inovaçáo, como continuidade dos achados de Ter Wal et al. (2017), Daspit et al. (2018), Frank et al. (2019) e Alves e Gama (2020). Outra sugestão é considerar a heterogeneidade da empresa familiar indicada por Neubaum et al., 2019), bem como os atributos da família nos negócios, indicados por Combs e Shanine (2020) para avançar no campo de pesquisa.

\section{Referências}

Alves, C. A., \& Gama, A. P. M. (2020). A performance das empresas familiares: uma perspectiva da influência da família. Revista Brasileira de Gestão de Negócios, 22(1), 163-182.

Andersén, J. (2015). The absorptive capacity of family firms: how familiness affects potential and realized absorptive capacity. Journal of Family Business Management, 5(1), 73-89.

Audy, J. (2017). A inovação, o desenvolvimento e o papel da universidade. Estudos Avançados, 31(90), 75-87.

Ayres, L. C. N., Cruz, V. L., Santos, R. R, \& Leone, R. J. G. (2018). Controle interno em empresas familiares de pequeno porte: uma aplicação do modelo COSO II. Revista da Micro e Pequena Empresa, $12(1), 3-17$. 
Barbetta, P. A. (2002). Estatística às ciências sociais. Florianópolis: UFSC.

Barboza, R. A. B., Fonseca, S. A., Ramalheiro, G. C. F. (2015). Inovação em micro e pequenas empresas por meio do serviço brasileiro de respostas técnicas. Revista de Administração e Inovação, 12(3), 330-349.

Brasil (2006). Lei Complementar no 123, de 14 de dezembro de 2006. Institui o Estatuto Nacional da Microempresa e da Empresa de Pequeno Porte. Brasília, DF. Recuperado em 21 de novembro, 2018, de http://www.planalto.gov.br/ccivil_03/Leis/LCP/Lcp123.htm.

Brasil (2004). Lei no 10.973, de 02 de dezembro de 2004. Dispóe sobre incentivos à inovação e à pesquisa científica e tecnológica no ambiente produtivo e dá outras providências. Brasília, DF. Recuperado em 21 de novembro, 2018, de http://www.planalto.gov.br/ccivil_03/_Ato2004-2006/2004/ Lei/L10.973.htm.

Campos, L. B. P., Campos, R., J. (2013). Análise multi-casos de gestão da inovação em empresas de pequeno porte. Pretexto, 14(1), 36-51.

Campos, M. G., Santos, D. F. L., \& Donadon, F. A. B. (2018). Impacto dos investimentos em inovação na indústria brasileira. Revista Gestão Industrial, 13(3), 213-236.

Chua, J. H., Chrisman, J. J., \& Sharma, P. (1999). Defining the family business by behavior. Entrepreneurship Theory and Practice, 23, 19-40.

Chua, J. H., Chrisman J. J., Steier, L. P., \& Lau, S. B. (2012). Sources of heterogeneity in family firms: an introduction. Entrepreneurship Theory and Practice, 36(6), 1103-1113.

Combs, J. G., \& Shanine, K. K. (2020). What do we know about business families? Setting the stage for leveraging family science theories. Family Business Review, 33(1), 38-63.

Costa Silva, L., Bezerra Ribeiro, A., Frascaroli, B., \& de Moraes Filho, R. (2018). Análise do processo inovativo em pequena empresa: estudo de caso a partir do Programa Agentes Locais de Inovaçáo. Revista de Empreendedorismo e Gestão de Pequenas Empresas, 7(1), 162-194.

Crossan, M. M., \& Apaydin, M. (2010). A multi-dimensional framework of organizational innovation: a systematic review of the literature. Journal of Management Studies, 47(6), 1154-1191. Doi:10.1111/ j.1467-6486.2009.00880.x

Dalla Corte, V. F., \& Waquill, P. D. (2015). Inovação na indústria de derivados de trigo no Brasil. Organizaçóes Rurais \& Agroindustriais, 17(4), 479-490.

Daspit, J. J., Long, R. G., \& Pearson, A. W. (2018). How familiness affects innovation outcomes via absorptive capacity: a dynamic capability perspective of the family firm. Journal of Family Business Strategy, 10(2), 133-143.

Davies, A., Dodgson, M., \& Gann, D. (2016). Dynamic capabilities in complex projects: the case of London Heathrow Terminal. Project Management Journal, 47(2), 26-46. 
De Massis, A., Di Minin, A., Frattini, F. (2015). Family-driven innovation: resolving the ability and willingness paradox to unlock the innovation potential of family firms. California Management Review, 58(1), 5-19.

Frank, H., Kessler, A., Bachner, C., Fuetsch, E., \& Suess-Reyes J. (2019). Principles for innovation management in family firms: an analysis of long-term successful good practices with a practitioner validation of the principles. Journal of Family Business Management, 9(3), 319-348. Doi: 10.1108/ JFBM-09-2018-0049.

Gersick, K. E., Davis, J.A, Hampton, M. M., \& Lansberg, I. (1997). De geração para geração: ciclos de vida das empresas familiares. Rio de Janeiro: Negócio.

Hair, J., Jr., Babin, B., Samouel P., \& Money A. (2007). Fundamentos de métodos de pesquisa em administração. Porto Alegre: Bookman.

Hatak, I., Kautonen, T., Fink, M., \& Kansikas, J. (2016). Innovativeness and family-firm performance: the moderating effect of family commitment. Technological Forecasting and Social Change, 102, 120-131.

Kammerlander, N. \& Breugst, N. (2019). Construals matter: paiting the big pictures or drawing the brushstrokes of the family firm. Family Business Review, 32(3), 222-232.

Kogut, C. S., \& Fleck, D. (2017). Professional versus family management in Brazilian fashion retail companies: exploring value-investors' perceptions. Cadernos Ebape.br, 15(3), 559-573.

Neubaum, D. O., Kammerlander, N., \& Brigham, K. H. (2019). Capturing family firm heterogeneity: how taxonomies and typologies can help the field move forward. Family Business Review, 32(2), 106130.

Nogueira, M. O. (2017). Um pirilampo no porão: um pouco de luz nos dilemas da produtividade das pequenas empresas e da informalidade no Brasil. Brasília: Ipea.

OCDE. Organização Para Cooperação e Desenvolvimento Econômico (1997). Manual de Oslo: diretrizes para a coleta e interpretaçáo de dados sobre inovação. São Paulo: Financiadora de Estudos e Projetos/FINEP.

Oliveira, J., Escrivão, E., Filho, Nagano, M. S., \& Ferraudo, A. S. (2015). Managerial styles of small business owners: a study based on the organizational life cycle and on concepts concerning manager's functions and roles. Review of Business Management, 17(57), 1279-1299.

Padilla-Meléndez, A., Dieguez-Soto, J., \& Garrido-Moreno, A. (2015). Pesquisa empírica sobre inovação na empresa familiar: revisão de literatura e proposta de estrutura integrativa. Revista Brasileira de Gestão de Negócios, 56(17), 1064-1089.

Parida, V., Westerberg, M., \& Frishammar, J. (2012). Inbound open innovation activities in high-tech SMEs: the impact on innovation performance. Journal of Small Business Management, 50(2), 283-309.

Payne, G. T. (2020). Family Business Review in 2020: focus on the family. Family Business Review, 33(1), 6-9. 
Pereira, M. F., Grappegia, M., Emmendoerfer, M. L., \& Três, D. L. (2009). Fatores de inovação para a sobrevivência das micro e pequenas empresas no Brasil. Revista de Administração e Inovação, 6(1), 50-65.

PINTEC. Pesquisa e Inovação. IBGE -Instituto Brasileiro de Geografia e Estatística. 2014 disponível em: https://www.ibge.gov.br/estatisticas/multidominio/ciencia-tecnologia-e-inovacao/9141-pesquisa-deinovacao.html?edicao=9142\&t=sobre. Acesso em: 27 out. 2020.

Prefeitura Municipal de Marau. História de Marau. Recuperado em 22 de abril, 2018, de https:// pmmarau.com.br/conheca-marau/historia-de-marau.

Qiu, H., \& Freel, M. (2020). Managing family-related conflicts in family businesses: a review ad research agenda. Family Business Review, 33(1), 90-113.

Scherer, F. O., \& Carlomagno, M. S. (2016). Gestão da inovação na prática: como aplicar conceitos e ferramentas para alavancar a inovaçáo. São Paulo: Atlas.

Schumpeter, J. A. (1982). Teoria do desenvolvimento econômico. São Paulo: Abril Cultural.

Silva, G., \& Dacorso, A. L. R. (2013). Inovação aberta como uma vantagem competitiva para a micro e pequena empresa. Innovation \& Management Review, 10(3), 251-268.

Silva, G., \& Dacorso, A. L. R. (2014). Processo de inovação na micro e pequena empresa: implicaçóes e achados em empresas sergipanas. Pensamento Contemporâneo em Administração, 8(3), 55-70.

Silva, G., \& Dacorso, A. L. R. (2016). O papel das fontes de conhecimento externo no processo de inovação da micro e pequena empresa. Desenvolvimento em Questão, 14(37), 231-261. Doi: 10.21527/2237-6453.2016.37.231-261.

Silva, M. A. C., Botelho, L. H., \& Rodrigues, L. C. (2016). O papel da inovação na gestão do modelo de negócios em pequenas empresas. Desafio Online, 4(3), 1-23.

Silva, M. C., Rampasso, I. S., Anholon, R., Ordoñez, R. E. C., Quelhas, O. L. G., \& Silva, D. (2018). Critical success factors of brazilian business incubators. Latin American Business Review, 19(3-4), $197-$ 217. Doi: 10.1080/10978526.2018.1534545

Ter Wal, A. L. J., Criscuolo, P., \& Salter, A. (2017). Making a marriage of materials: the role of gatekeepers and shepherds in the absorption of external knowledge and innovation performance. Research Policy, 46(5), 1039-1054.

Zahra, S. A., Hayton, J. C., Neubaum, D. O., Dibrell, C., \& Craig, J. (2008). Culture of family commitment and strategic flexibility: the moderating effect of stewardship. Entrepreneurship Theory and Practice, 32(6), 1035-1054. 